\title{
Passagem e Progresso na Antropologia de Kant
}

[Passage and Progress in Kant's Anthropology]

$$
\text { Antonio Djalma Braga Junior }
$$

Resumo: Esse artigo tem como objetivo analisar como a antropologia pode representar um modo de realização da passagem entre liberdade e natureza no pensamento de Kant. Assim, pretendemos deixar claro que o problema inaugurado nas introduções à Crítica da Faculdade de Julgar, sobre a possibilidade de uma passagem entre o abismo aparentemente intransponível da liberdade e da natureza se torna possível não apenas a partir das reflexões realizadas sobre a faculdade de julgar e suas implicações nos juízos de gosto sobre o belo e nos juízos de finalidade, mas, também, a partir da tese do progresso presente na filosofia da história de Kant que recebe uma de suas formas de realização nas questões que envolvem a natureza humana (antropologia).

Palavras-chave: passagem; progresso; liberdade; natureza; antropologia.

\begin{abstract}
This article aims to analyze how anthropology can represent a way of realization of the passage between freedom and nature in Kant's thought. Thus, we want to make it clear that the problem inaugurated in the introductions to the Critique of Judgement about the possibility of a passage between the immeasurable gulf of freedom and nature becomes possible not only from the reflections made on the faculty of judgment and its implications in judgments of taste over the beautiful and in the judgments of purpose but also from the thesis of progress presented in the Kant's philosophy of history which receives one of its forms of realization in matters involving human nature (anthropology).
\end{abstract}

Keywords: passage; progress; freedom; nature; anthropology.

\footnotetext{
${ }^{*}$ Professor da Universidade Positivo. Doutor em Filosofia pela Universidade Federal do Paraná. E-mail: antonio.djalma@hotmail.com. ORCID: https://orcid.org/0000-0002-3998-8373.
} 


\section{Introdução}

Discutir a antropologia kantiana é discutir uma ciência diferente do que pensava seus contemporâneos e até mesmo seus sucessores. Um dos intérpretes que procura analisar a antropologia kantiana nessa linha de pensamento é Robert Louden!; “a antropologia kantiana, de forma significativa, é um campo de estudo único que não deve ser automaticamente igualado a antropologias não-kantianas" (LOUDEN, 2002, p. 28). Ele resume as características da antropologia kantiana em alguns pontos que julga ser de fundamental importância, ainda que esta seja uma tarefa arriscada.

Primeiramente desenvolve a ideia de que a antropologia kantiana é uma ciência empírica, ou melhor, uma doutrina baseada na experiência, uma Beocachtungslehre (Cf. KANT, Br 1773, AA 10: 145146); em seguida, defende que ela é uma ciência cosmopolita, pois ela teria como objetivo o conhecimento do ser humano como um cidadão do mundo, devendo, portanto, ser um antropologia geral e não local, é uma descrição não de grupos específicos, mas da natureza humana como um todo (Cf. KANT, Anth, AA 07: 120, cf. ); para depois afirmar que a antropologia é uma ciência pragmática, em oposição à uma antropologia fisiológica defendida por interlocutores como Ernst Platner e outros. Nessa perspectiva, a antropologia fisiológica se preocuparia com a investigação do que a natureza faz do ser humano, enquanto a pragmática voltaria sua atenção para a investigação do que ele faz dele mesmo como agente livre, ou melhor, do que o homem pode e deve fazer de si mesmo no uso de sua liberdade (Cf. KANT, Anth, AA 07: 119).

Assim, a antropologia pragmática tem como objetivo um conhecimento popular e útil não apenas para ser ensinado na escola, mas também para ser ensinado na vida e no mundo. Ela é útil tanto para ser aplicada no intuito de transformar a nós mesmos, quanto para nos auxiliar em nossas escolhas para a felicidade e o bem-estar, em um sentido de prudência (Klugheit) (Cf. KANT, GMS, AA 04: 416, cf. $\mathrm{KrV}$ A806/ B834). Desse modo, Louden escreve que "a antropologia pragmática fortalece essa habilidade, na medida em que o conhecimento da natureza humana, que adquirimos dela, nos capacita para usar eficazmente outros seres humanos para os nossos próprios

\footnotetext{
${ }^{1}$ Cf. LOUDEN, R. "A Segunda parte da Moral” : a Antropologia Moral de Kant e sua relação com a Metafisica dos Costumes. Revista Ethic@, Florianópolis, vol 1, nº 1, p. 27-46, 2002.
} 
propósitos" (LOUDEN, 2002, p. 32).

Entretanto, Louden afirma ainda que podemos entender uma outra perspectiva sobre a antropologia em Kant, diferente de todas as que foram apresentadas até aqui. Se trata de uma dimensão fundamental da antropologia e que se denomina Antropologia Moral. Assim, a antropologia é entendida em uma dupla significação, em duas partes.

Quem também analisa a antropologia de Kant em uma dupla perspectiva é Manfredo Araújo de Oliveiral2, Em seu artigo $A$ Antropologia na Filosofia de Kant (1978) ele fala, em primeiro lugar, de uma antropologia do ponto de vista de uma verdadeira reflexão de ordem filosófica, pensada e analisada transcendentalmente, de modo que o homem e sua subjetividade finita determinam o conjunto de condições de possibilidade do conhecimento e das ações humanas; a antropologia procura responder ao questionamento sobre o que é o homem sem recorrer à uma concepção de ordem empírica. De outro lado, fala de uma antropologia, em Kant, que leva em consideração a ordem empírica sobre o que é o homem e que ele denomina, propriamente, de
Antropologia. Oliveira chama esse primeiro tipo de Antropologia Pura e o segundo tipo apenas de Antropologia (ou de Antropologia-objeto):

A primeira Antropologia é o que se poderia chamar a "Antropologia Pura", pois se realiza, unicamente, através da reflexão transcendental, sem apoio da empiria. Ela tem a ver com a própria estrutura fundamental do homem enquanto é possível conhecê-la através de uma reflexão transcendental, enquanto aquilo que Kant chama, propriamente, de Antropologia tem como objeto o homem fático, cuja realidade conhecemos através da experiência (OLIVEIRA, 1978, p. 1247).

Nesse ponto de vista, podemos perceber que enquanto a Antropologia Pura procura definir qual é a essência do homem de um ponto de vista transcendental, alinhado ao sistema Crítico de Kant, a Antropologia-objeto revela-se na análise do homem factual, visto empiricamente, vivendo suas pe-

\footnotetext{
${ }^{2}$ Cf. OLIVEIRA, M. A. A antropologia na filosofia de Kant. Revista de Ciências sociais, vol. IX, no 1 e 2 pág. 127-140, 1978.
} 
ripécias e sendo vocacionado a viver uma vida racional e livre: "tudo isto nos mostra, que a antropologia-objeto descreve o homem como um ser mundano, condicionado pela realidade circundante, e interpelado, como ser consciente, a caminhar na direção da racionalidade, isto é, da liberdade (OLIVEIRA, 1978, p. 138).

O que pretendemos nesse artigo é apresentar as mais variadas formas de entender a antropologia de Kant de modo que possamos compreender em que medida ela pode ser analisada como um modo de realização e de um sentido de passagem em Kant.

Para construirmos nosso argumento, vamos analisar primeiramente a antropologia em sua relação com a filosofia da história a partir das teses do progresso e da sociabilidade insociável do homem, para, em seguida, compreender como a essência do homem passa a ser definida no idealismo Crítico, de modo que compreendamos o alcance sistemático da antropologia em um possível sentido de passagem (da teoria à prática, ou da primeira para a segunda Crítica) e, por fim, nos deter na ideia da antropologia como uma segunda parte da moral kantiana, de modo que possamos entendêla como uma forma de realização da passagem da liberdade à natureza e que pode ser realizada no curso da história da humanidade (não como indivíduo, mas como espécie), de modo que a Natureza cumpra com o seu propósito de desenvolver todas as disposições naturais no homem, que culmina em sua destinação moral.

\section{1 - Antropologia e Filosofia da História de Kant}

Na obra Antropologia de um ponto de vista pragmático Kant entende o caráter da espécie humana como aquilo que é conhecido de antemão na sua destinação e se questiona como é possível essa determinação (KANT, Anth, AA 07: 329). A resposta a esse questionamento é difícil de se obter, ou melhor, esse é um problema insolúvel, uma vez que determinar isso exigiria um trabalho de comparação entre duas espécies de seres racionais de maneira a posteriori e isso seria impossível de ser realizado.

Justamente por falta dessa possibilidade de comparação é que não se pode determinar com precisão o que é específico da natureza humana como um ser dotado de racionalidade. Mas o que se pode fazer diante disso? Nada mais nos resta a não ser afirmar que seu caráter é criado para si enquanto esse ser é capaz de se aperfeiçoar segundo fins que ele 
mesmo assume para si: desse modo, o ser humano, animal dotado de uma faculdade da razão (animal rationabile), pode se fazer um animal racional (animal rationale).

Ao se fazer um animal racional, esse ser humano consegue conservar sua espécie e a si mesmo, tal como treinar seu aspecto físico, se instruir e se educar para a vida em sociedade e governá-la como um todo sistemático ordenado segundo princípios próprios da razão (Cf. KANT, Anth, AA 07: 321-322). Como afirma Joel Thiago Klein:

A caracterização do homem como animal rationabile rompe com a tradição, pois traz à tona um caráter histórico da razão. O homem não é um ser que está no pleno uso de suas capacidades racionais. Ele precisa se educar, para que a razão se esclareça a respeito de suas próprias potencialidades e limites. Por isso, a consideração antropológica do homem também conduz, por sua vez, a uma consideração histórica da espécie (KLEIN, 2016, p. 99-100, itálico nosso).
Fica explicitado, assim, uma via de mão dupla no pensamento kantiano entre a filosofia da história e a antropologia. E ainda que tal consideração possa levantar algumas dificuldades interpretativas, vale ressaltar que é sempre uma e mesma razão que se manifesta na espécie humana, sendo que não é a razão que se modifica ao longo da história, mas apenas as disposições racionais no homem que se tornam mais esclarecidas.

Essa mudança que vemos da razão humana na história não é uma mudança estrutural, mas é um desenvolvimento de algo que já estava presente desde o início da espécie humana, pois todos os indivíduos são dotados igualmente de racionalidade e a Natureza os dotou com as mesmas disposições originárias: "as faculdades são sempre as mesmas; o que pode mudar é seu uso, que se torna mais ou menos adequado, mais ou menos esclarecido" (KLEIN, 2016, p. 103). É desse modo que podemos conhecer também o caráter a-histórico da filosofia da história kantiana e ainda o status de um conhecimento regulativo da razão que esta concepção pressupõe.

É a partir desses pontos trabalhados que Klein fará uma investigação minuciosa sobre as teses antropológicas da sociabilidade insociável, da relação entre moral e política e, ainda, dos aspectos pe- 
dagógicos e institucionais necessários ao progresso na história e que nos servirá de base para pensarmos esse aspecto da antropologia no pensamento de Kant.

Começamos nossa análise, nessa parte desse artigo, sobre o antagonismo da sociabilidade insociável no homem.

\section{1 - A Tese Antropológica da So- ciabilidade Insociável e o Pro- gresso na História}

A tese do antagonismo do homem representa, de um lado, a inclinação (Neigung) para se socializar (vergesellschaften) e, de outro, a propensão (Hang) a se isolar (vereinzelnen). Como Kant escreve na quarta proposição da IaG:

O homem tem uma inclinação para associar-se porque se sente mais como homem num tal estado, pelo desenvolvimento de suas disposições naturais. Mas ele também tem uma forte tendência a separar-se (isolar-se), porque encontra em si ao mesmo tempo uma qualidade insociável que o leva a querer conduzir tudo simplesmente em seu proveito, esperando oposição de todos os lados, do mesmo modo que sabe que está inclinado a, de sua parte, fazer oposição aos outros (KANT, $I a G$, AA 08: 20, p. 08, grifo nosso).

O que se pode perceber aqui é que, por um lado, a sociabilidade é uma tendência do homem que pretende efetivar sua natureza racional, um impulso para realizar aquilo que nele se encontra apenas germinando e, por outro lado, a insociabilidade representa uma propensão ao isolamento que está latente em cada indivíduo, uma vontade de querer fazer as coisas ao seu gosto, de exercer suas vontades sobre os demais indivíduos e de evitar fazer a vontade dos demais sobre si.

É nesse sentido que podemos entender que Kant escreva na Anth que a Natureza pôs nos homens o germe da discórdia e quis que ele transformasse essa em concórdia, na ideia de um fim onde pudesse realizar o aperfeiçoamento do ser humano através do estabelecimento da cultura (Cf. KANT, Anth, AA 07: 321). Ou ainda, como ele descreve na $Z e F$, quando fala que através da discórdia os homens podem fazer surgir a harmonia (Cf. KANT, ZeF, AA 08: 360).

O fato é que por meio dessa noção de antagonismo nós podemos compreender que os homens 
desenvolvem seus talentos, uma vez que, se não houvesse tal antagonismo, permaneceriam sempre adormecidos, por conta da preguiça que lhe é inerente. Sem essa característica antagônica, os indivíduos tenderiam à inércia. Outro fator importante dessa sociabilidade insociável do homem é que ela não opera apenas no indivíduo, mas também no Estado, uma vez que os corpos políticos tendem a reproduzir os mesmos traços dos indivíduos.

A mesma insociabilidade, que obrigou os homens a criar um Estado, atua novamente na relação exterior, de forma que "cada um deve esperar do outro os males que pressionaram e constrangeram os homens singulares a entrar em um estado civil legal" . Por meio das guerras e da constante preparação para ela, condição que exaure as forças internas dos Estados, a Natureza os compele a "sair do estado sem leis dos selvagens e ingressar em uma liga de povos (...)" (KLEIN, 2016, p. 107).

A Natureza ordenou as coisas para os homens pudessem se desenvol- ver a partir desse antagonismo, para que da discórdia pudesse surgir concórdia, das guerras pudesse surgir a paz. Essa sociabilidade insociável funciona como uma mola propulsora do progresso na humanidade de modo que todas as suas disposições naturais possam se desenvolver ao longo da história.

Todavia, embora esse antagonismo antropológico seja de fundamental importância para pensarmos o progresso, certamente ele não é a única e definitiva solução que a Natureza propôs para a humanidade desenvolver suas disposições. Como os seres humanos são seres livres, o progresso também precisa ser fruto de uma escolha. É nesse sentido que podemos analisar a sexta proposição da $I a G$ de Kant (AA 08: 23).

(...) o homem é um animal que, quando vive entre outros de sua espécie, tem necessidade de um senhor. (...) ele tem necessidade de um senhor que quebre sua vontade particular e o obrigue a obedecer à vontade universalmente validade, de modo que todos possam ser livres.

Mas de onde deve-se tirar alguém justo o suficiente para ser o senhor que garanta a liberdade de todos? Deve-se tirar da própria espécie humana. Essa é a tarefa mais 
difícil de todas, pois o supremo chefe deve ser escolhido na espécie humana e, ao mesmo tempo, ele deve ser justo por si mesmo e isso é um problema porque, como diz Kant na famosa metáfora do lenho retorcido: "de uma madeira tão retorcida, da qual o homem é feito, não se poder fazer nada reto" (KANT, IaG, AA 08: 23).

Mas como garantir que esse senhor não abuse de sua liberdade, abrindo exceções a leis e fazendo com que haja, ao invés de um progresso, um regresso infinito? Para que isso ocorra, se faz necessário a criação de um Estado Civil Perfeito, fundado em uma Constituição Republicana, de modo que se cumpra as três condições que Kant elenca no final dessa sexta proposição e que é ordenada pela Natureza: que se tenha o conhecimento de conceitos exatos de uma constituição possível; tenha também grande experiência sobre $o$ curso do mundo; e, acima de tudo, possuir uma boa vontade para aceitar essa constituição civil.

Para alcançar essas condições, se faz necessário que o senhor seja esclarecido moralmente e nisso reside a maior dificuldade de efetivação deste propósito, pois é difícil (ou praticamente impossível) que se encontre um senhor assim, ao menos é isso que a metáfora do lenho retorcido descrita acima quer nos mostrar. Desse modo, tanto a tese da sociabilidade insociável, como essa metáfora do lenho retorcido de Kant nos apontam para uma constatação antropológica no qual a possibilidade de um progresso na história nos apresenta e da qual temos de analisar para podermos pensar a possibilidade de passagem entre liberdade e natureza.

É sobre isso que iremos ver nos próximos dois tópicos desse artigo.

\section{2 - Antropologia e Passagem no Sistema Crítico de Kant}

Em seu texto Crítica e Antropologia, Vinicius Berlendis de Figueiredo realiza uma investigação mais ampla acerca da antropologia em Kant para reaver o alcance sistemático que a questão do homem possui no Idealismo Crítico. Para esse empreendimento, ele toma como referência dois intérpretes clássicos kantianos, a saber, Lebrun e Philonenko.

Segundo Figueiredo, o que estes dois intérpretes fazem contribui para uma visão original do estatuto da antropologia na filosofia Crítica de Kant sobretudo no que diz respeito ao elo entre esses dois elementos (Antropologia e Crítica). Esse elo é reativado, segundo Figueiredo, a partir da crítica ao dogmatismo e, com efeito, à fini- 
tude humana. Kant, ao pôr fim ao dogmatismo, limitando os conhecimentos aos fenômenos, nos mostra como esses elementos da Crítica e da Antropologia estão entrelaçados.

Logo no início da $\mathrm{KrV}$ (A247/ B303) podemos ver o problema que a razão humana nos impõe e do qual não podemos nos livrar, mas que não podemos dar uma resposta por transcender nossas possibilidades. Isso quer dizer que há questões que possuem um forte apelo e significação de nossa parte, mas que por sermos finitos, não conseguiremos jamais dar uma resposta objetiva. Figueiredo chama a atenção para esse fato e para a distinção que se pode fazer, no pensamento de Kant, entre razão tomada em si mesma e a razão humana, entre a razão como objeto indireto de uma oração e ao mesmo tempo como sujeito ${ }^{3}$. Essa distinção é importante por demonstrar que a razão possui diversas acepções e sentidos.

Isso que é anunciado no início da $K r V$ tem sua origem no movimento de totalização da razão a partir do condicionado para condições e questões cada vez mais remotas. Com efeito, esse movimento de totalização produz uma ilusão que não pode ser evitada (KvR A297/ B 353). Importante frisar aqui que esta ilusão, uma ilusão necessária, é diferente de ser enganado: iludido sim, enganado não. Essa ilusão racional é útil e representa um ganho à $f a$ culdade de julgar, que poderá se beneficiar dessa vocação sistemática da razão quando recusa o dogmatismo. São questões como essas que levam Kant a efetuar a divisão da Crítica em uma Analítica e uma Dialética, enquanto na primeira ele analisa a lógica da verdade, na segunda ele se preocupa em estabelecer uma crítica da ilusão. Desse modo, as exigências de significação das coisas as quais não se pode dar uma resposta objetiva agora são justificadas como exigências da razão, como condição de possibilidade do conhe-

\footnotetext{
${ }^{3}$ Figueiredo faz essa análise a partir do que diz Kant no primeiro parágrafo do prefácio A da KrV (A, VII), publicada em 1781: "Die menschliche Vernunft hat das besondere Schicksal in eiber Galtung ihrer Erkenntnisse: dass sie durch Fragen belästigt wird, die sie nicht abweisen kann, denn sie sind ihr durch die Nature der Vernunft selbst aufgegeben, die sie aber nicht beantworten kann, denn sie übersteigen alles Bermögen der menschlichen Vernunft" (KrV, A VII). Figueiredo procura destacar as dificuldades de tradução desse trecho, comparando a tradução de Manuela Pinto dos Santos e Alexandre Fradique Morujão na edição da Fundação Calouste Gulbenkian de 2008 com a tradução italiana de Giovanni Gentile e Giuseppe Lombardo-Radice de 1949. Para ele, a tradução italiana é que mais se aproxima do enigma do texto original e considera que "se é preciso transpor o âmbito da Analítica do entendimento, é porque há questões que a 'razão humana' (die menschliche Vernunft) não pode evitar, impostas que são pela 'natureza da razão' (Natur der Vermimft), mas às quais também 'não pode dar resposta por ultrapassarem completamente as suas possibilidades'”. . E conclui que "a natureza da razão impõe à razão humana" , decorre daí o problema de, conceitualmente, explicar que a razão humana figure, ao mesmo tempo, como sujeito e objeto indireto da mesma frase, a não ser que a ideia de razão humana possa ser tomada em acepções distintas (Cf. FIGUEIREDO, 2010, p. 126)
} 
cimento empírico (Cf. FIGUEIREDO, 2010, p. 126). Em outras palavras, o que Figueiredo quer nos mostrar é que existe uma mútua remissão entre racionalidade e finitude humana e essa relação não produz apenas conclusões no âmbito da epistemologia, mas também produz no campo da prática, da moral. Nesse sentido, são as ideias racionais que fornecerão os parâmetros para o agir humano.

Aqui chegamos ao ponto que interessa de fato ao nosso artigo sobre a análise de Figueiredo, pois a passagem de uma Crítica à outra ocorrerá a partir da afirmação de que se trata de uma mesma e única razão. Esse sentido de passagem é importante para demonstrar essa característica totalizante da razão que, agora, descrita de um modo teórico na $K r V$ e de um modo prático na $K p V$, se pode visualizar. Assim, o conceito de Liberdade é tanto um elemento da Analítica como também "o fecho da abóboda de todo o edifício de um sistema da razão pura, mesmo da razão especulativa, e todos os demais conceitos (os de Deus e de Imortalidade) (...) (KpV, A $4 / 5)$. Somente através do realinhamento dos elementos que podemos verificar na doutrina transcendental e, com efeito, na passagem da primeira para a segunda Crítica é que a unidade da razão vai adquirir um estatuto de prin- cípio demonstrado. A passagem sobre a qual Kant escrevia na GMS (da metafísica da natureza à metafísica dos costumes) não possuía a comprovação da unidade da razão a partir de um princípio comum, fato que somente em 1788, com a publicação da $K p V$ ficará evidenciado, somente com a passagem da primeira para a segunda Crítica,

(...) quando o incondicionado posto pela razão a título de princípio de inteligibilidade do conhecimento empírico se revela, enquanto liberdade, fundamento de determinação da ação moral, e, enquanto imortalidade da alma e existência de Deus, postulados sem os quais a moralidade seria incompatível com a felicidade. Essa reorganização temática vai de par com o princípio de exposição dos textos: somente tendo em conta a unidade da razão, compreende-se que a doutrina dos elementos da $2^{\circ}$ Crítica seja a perfeita acomodação dos temas da metafísica especial (liberdade, alma e Deus), cuja pretensão teórica, contestada por Kant na Crítica da Razão Pura, dá lugar à vocação 
última da razão para a moral e a religião. (FIGUEIREDO, 2010, p. 129)

É aqui, nesse ponto, que Figueiredo analisa a questão antropológica e suas implicações com o projeto Crítico de Kant, dizendo que na passagem da teoria à prática surge um princípio regulador que se torna constitutivo, mediante o qual a razão passa a exigir uma ampliação do uso do entendimento no âmbito do conhecimento empírico.

Dito com outras palavras, é na passagem da primeira para a segunda Crítica de Kant que o princípio da reflexão sobre a natureza passa ter reflexos na ação moral como um fundamento de determinação: "as determinações da razão prática submetem 'o múltiplo das apetições à unidade da consciência de uma razão prática, ou de uma vontade pura a priori, que ordena na lei moral'"' (FIGUEIREDO, 2010, p. 129).

Diante dessas explicações, Figueiredo (2010, p. 129-130) passa a analisar a ideia central de seu artigo dizendo que a finitude do homem, entendido em um duplo sentido, é a base para se pensar a passagem da primeira para a segunda Crítica, ou como ele próprio escreve:
(...) de um lado, a limitação do conhecimento especulativo ao âmbito dos fenômenos, a partir da qual $o$ incondicionado ganha o estatuto transcendental de "simples ideia" na Dialética transcendental, mobiliza como fator decisivo de sua reformulação crítica a natureza sensível de nossa intuição (estética transcendental). (...) De outro lado, a moralidade é definida da Crítica da Razão Prática em diante como adoção de uma máxima baseada no mandamento da razão em oposição direta aos móbiles patológicos, o que configura um conflito que, além de ensejar a doutrina do livre arbítrio, só faz sentido tendo em vista o estatuto singular da vontade de um ser a um só tempo racional e sensível.

Em suma, o que Figueiredo quer nos mostrar é que a passagem da teoria à prática, ou ainda, a passagem da natureza à liberdade exige um compromisso de fundo com a questão antropológica. Essa passagem só tem sentido se a finitude do homem for pensada positivamente, de modo que a referência à natureza humana aparece como decisivo na teoria, na prática, e 
também como um elemento que articula a passagem de um ao outro, como uma referência constitutiva da epistemologia transcendental, da doutrina da moralidade e da articulação entre uma e outra parte da filosofia e perguntar sobre o estatuto desse elemento constitutivo que articula esses domínios distintos nos leva à $K d U$. Figueiredo afirma que a unidade da razão se completa, o sistema crítico só cessa quando encontra o princípio transcendental da faculdade do juízo que dispõe de um princípio a priori, puramente subjetivo, que é, a saber, o princípio da finalidade, tal como defendido por Lebrun.

Nesse sentido, podemos concluir aqui que a questão antropológica da finitude humana se torna fundamental para entendermos um dos modos de realização da passagem da liberdade à natureza, do âmbito da filosofia teórica à prática.

Vamos ver agora como essa passagem pode ser pensada a partir de uma perspectiva da antropologia tomada como a segunda parte da moral em Kant e que é chamada de Antropologia Moral.

\section{3 - Antropologia Moral e Passa- gem em Kant}

Como podemos constatar, temos em Kant uma Metafísica dos Costumes, ou ainda, uma metaphysica pura que compõe a primeira parte da moral, e uma segunda parte que seria a philosophia moralis applicata, da qual fazem parte os princípios empíricos que a ela pertencem. A antropologia moral estaria situada no campo dessa moralidade aplicada aos seres humanos. Louden afirma sobre essa distinção o seguinte:

Em seus escritos e lições de ética após 1770, Kant repetidamente evoca o termo "antropologia" quando descreve essa segunda parte, empírica, da ética. Frequentemente, como nas duas citações anteriores, a frase favorecida é "antropologia moral"; às vezes, "antropologia prática" ( $G r$ 4:388), e às vezes, simplesmente, "antropologia" (Gr 4:412, Collins 27:244, Mrongovius I 27:1398). Esse emprego frequente dentro das obras de filosofia prática de Kant do termo "antropologia" como um meio rápido de se referir ao "outro membro da divisão da filosofia prática 
como um todo" dá aos leitores que procuram suas lições de antropologia, uma expectativa legítima de que os detalhes da philosophia moralis applicata de Kant serão finalmente tratadas com algum detalhe (LOUDEN, 2002, p. 33)

O problema é que Kant nunca chegou a dizer de maneira detalhada o que seus leitores procuravam em suas lições de antropologia, de modo que as expectativas de uma explicação sobre o que ele chamava de antropologia moral nunca foram de fato atendidas. Kant nunca detalhou de que maneira essa segunda parte da moral se relacionaria com a primeira, ou seja, como essa parte empírica se relacionaria com a parte nãoempírica e muito menos chegou a explicar o porquê essa antropologia (como segunda parte da moral) seria constituinte da primeira. O que temos, de fato, são trechos de texto sobre o que Kant entendia dessa antropologia moral nos escritos sobre a história, educação, religião e ética, mas nada sistematizado ou organizado claramente para dar conta desse tipo de antropologia. Todavia, isso não deve ser motivo de lamento, pois como diz Louden:
(...) enquanto nós, infelizmente, não encontrarmos uma articulação abrangente e sistemática da "contraparte da metafísica dos costumes" em nenhuma lição de antropologia de Kant (ou em qualquer outro lugar de seus escritos), é definitivamente o caso de que elas reverberam fortemente, com múltiplas mensagens e implicações morais. Ao invés de continuamente lamentar o fato de que as lições de antropologia não nos fornecem uma caracterização explicita, sistemática e detalhada do "outro membro da divisão da filosofia prática como um todo, "antropologia moral", sugiro que nos voltemos para a tarefa mais construtiva de esclarecer e integrar essas mensagens morais (LOUDEN, 2002, p. $34)$.

O que precisa ser feito é um verdadeiro papel de detetive para encontrar o lugar dessa antropologia moral no sistema filosófico de Kant. Uma vez que Kant tenha afirmado em vários momentos que a moralidade não pode existir sem a antropologia convém a nós tentarmos dar um sentido a 
isso.

Louden consegue extrair pelo menos três mensagens centrais sobre a antropologia moral analisando as lições de antropologia de Kant: a) a primeira diz que é preciso tornar a moralidade algo efetivo na vida humana (Cf. LOUDEN, 2002, p. 35). Essa mensagem nos conduz a ideia de que uma antropologia desse tipo (moral) é útil à humanidade, pois tal conhecimento permite a nós nos transformar e nos aprimorar para nos tornar seres humanos melhores, ainda que seu uso tenha de ser entendido em um sentido prático e não meramente pragmático; b) a segunda mensagem afirma que a antropologia moral nos é útil como um conhecimento do mundo (Weltkenntnis) (LOUDEN, 2002, p. 38). Sem tal conhecimento do mundo, os princípios morais nunca poderão ser colocados em prática em um contexto humano (Cf. KANT, GMS, AA 04: 389; 412). Como diz Louden (2002, p. 39): "os seres humanos não podem simplesmente ir ao encontro com a ética pura, sem auxílio; um conhecimento básico da sua situação empírica é um prérequisito necessário se os princípios da ética pura devem ser de algum uso para eles" ; c) a terceira mensagem afirma que existe uma vocação das espécies humanas (Bestimmung). Essa mensagem nos conduz à ideia de que essa vocação, ou destinação, só pode ser alcançada pela espécie (e não pelo indivíduo), indicando uma relação com a noção de progresso na história e a necessidade tanto de uma educação como de uma organização política e social específica para que a humanidade consiga alcançar sua vocação coletivamente.

As instituições políticas, uma boa educação e os melhores conceitos de religião são os meios apropriados para promover essa Bestimmung nos seres humanos:

Em relação à primeira, a tarefa é desenvolver formas republicanas de governo, "onde cada cidadão tem que ter sua própria voz" (Mrongovius 25:1427); i.e., onde todos os cidadãos estão envolvidos no processo de fazer leis, e onde a liberdade, igualdade e independência de cada membro da sociedade é respeitada (cf. Gemeinspruch 8:290) (...). Em relação à segunda, (...) o aprimoramento da educação (...) [tinha como objetivo] ensinar os alunos a tornarem-se "cidadãos do mundo." (...) Em relação à religião - a terceira maneira de atingirmos nossa Bestimmung - 
a disciplina religiosa também é necessária, "para que o que não pode ser alcançado através da coerção externa, possa ser afetado através de uma coação interna (a coação da consciência)" (Anth 7:333n). (LOUDEN, 2002, p. 42).

Diante disso que foi apresentado, podemos perceber que as Lições de Antropologia de Kant podem nos fornecer indícios de uma antropologia moral específica que funciona como uma outra parte da $\mathrm{Me}$ tafisica dos Costumes.

Todavia, ainda que essas questões apresentem uma contribuição sobre a antropologia como um todo, também apresenta alguns problemas que não entraremos em detalhe aqui, mas que foram trabalhados por Louden em sua obra Kant's impure ethics: from rational beings to human beings ${ }^{4}$, uma vez que essa antropologia moral seria a parte impura da ética kantiana.

$\mathrm{O}$ que nos interessa aqui é que desses problemas surgem implicações em relação às ciências sociais como um todo, uma vez que o posicionamento de Kant diverge daquele que será defendido por Weber, a saber, de uma ciência social desprendida de valoração por parte do pesquisador. Ao contrário do que Weber descreve, Kant procura analisar as ciências sociais e a antropologia como um empreendimento carregado de valor por parte do pesquisador, pois tais investigações são guiadas pela moral e, como dito acima, deve nos auxiliar a nos tornar seres melhores e, consequentemente, melhorarmos nosso mundo, com o objetivo de criar um reino moral (Cf. LOUDEN, 2002, p. 44).

Esse ponto nos é interessante para o argumento central desse artigo porque vemos que o entendimento da antropologia, nesses termos, é uma forma de construir uma Übergang entre os reinos da liberdade e natureza, ou seja, a antropologia é um modo de realização possível da passagem entre esses dois domínios da filosofia de Kant. Nesse sentido, estamos de acordo com as palavras de Louden:

Conhecer a nós mesmos e ao nosso mundo cai sob o imperativo moral de tornar a nós mesmos e o nosso mundo moralmente melhores. Finalmente, buscamos o conhecimento antropológico, para levarmos adiante o objetivo de criar um reino moral; de construir o que Kant chamou de Übergang (passagem) entre a natureza e a liberdade (LOUDEN, 2002, p. 44). 
Louden está nos mostrando que a cisão entre ciência e valor deve ser repensada e que a antropologia kantiana indica um caminho oposto ao seguido por Weber, no sentido de que tal ciência deve sim ser imbuída de valor moral, ou seja, a antropologia deve ser guiada pela moral e o homem possui a necessidade de criação de estruturas jurídicas e políticas para que a realização das ideais morais criados pela razão em seu sentido prático (liberdade) possam se realizar no reino da natureza. Como veremos, tal realização é possível apenas na espécie humana e, por isso, a análise filosófica de Kant sobre a história se torna fundamental para compreendermos o desenvolvimento das disposições naturais dos seres humanos e a passagem da liberdade à natureza.

Nesse sentido, pretendemos nas próximas pesquisas demonstrar como essa passagem e a tese do progresso, analisada sob a ótica de uma filosofia política e de uma perspectiva da Educação em Kant, estão interligadas e assumem um papel central nos escritos sobre a filosofia da história, pois a passagem de uma vida natural para uma vida livre depende dos homens se organizarem politica e educacionalmente para que a humanidade possa atingir o seu fim e cumprir sua destinação moral por meio do estabelecimento de uma ordem in- ternacional racional e livre e que alcance todas as nações.

\section{Considerações Finais}

Esse artigo teve como intuito esclarecer que o problema inaugurado nas introduções à $K d U$ por Kant, sobre a possibilidade de uma passagem entre o abismo aparentemente intransponível da liberdade e da natureza, se torna possível não apenas a partir das reflexões realizadas sobre a faculdade de julgar e suas implicações nos juízos de gosto sobre o belo e nos juizos de finalidade mas, também, a partir da tese do progresso presente na filosofia da história de Kant que recebe uma de suas formas de realização nas questões que envolvem a natureza humana (antropologia).

Essa ideia está de acordo com o sistema Crítico de Kant, sobretudo no que diz respeito aos juízos teleológicos que ele apontou na $K d U$. Fizemos esse percurso até aqui para demonstrar que no curso da história os juízos teleológicos encontrarão outras formas de realização da passagem dos princípios do reino da liberdade para os do reino da natureza, no sentido de que o juízo ajuda a razão prática a construir a ideia de finalidade da humanidade que, como Kant destaca em sua filosofia da história, 
culminará na moralidade e que poderá ser vista na antropologia quando Kant indica um caminho (oposto ao seguido por Weber) de que a antropologia deve ser guiada pela moral e o homem possui a necessidade de criação de estruturas jurídicas e políticas para que a realização das ideais morais criados pela razão em seu sentido prático (liberdade) possam se realizar no reino da natureza. Como veremos, tal realização é possível apenas na espécie humana e, por isso, a análise filosófica de Kant sobre a história se torna fundamental para compreendermos o desenvolvimento das disposições naturais dos seres humanos e a passagem da liberdade à natureza.

\section{Referências}

KANT, Immanuel. Gesammelte Schriften. Hrsg.: Bd. 1-22 Preussische Akademie der Wissenschaften, Bd. 23 Deutsche Akademie der Wissenschaften zu Berlin, ab Bd. 24 Akademie der Wissenschaften zu Göttingen. Berlin 1900ss.

. Anthropologie in pragmatischer Hinsicht. Trad. Clélia Aparecida Martins. São Paulo, Iluminuras, 2006 (AA 07).

. Briefe. Bd. 10-13.

. Grundlegung zur Metaphysik der Sitten. Trad. Paulo Quintela. Lisboa: Edições 70, 2007. (AA $04)$.

. Idee zu einer allgemeinen Geschichte in weltbürgerlicher Absicht. Trad. Rodrigo Novaes e Ricardo

R. Terra. São Paulo: Martins Fontes, 2016. (AA 08).

Kritik der praktischen Vernunft. Edição Bilíngue. Trad. Valério Rohden. São Paulo: Martins Fontes, 2003. (AA 05).

. Kritik der reinen Vernunft. Trad. de Manuela Pinto dos Santos, 5a Edição. Lisboa: Fundação

Calouste Gulbenkian, 2001. (A 1781, B 1789).

. Kritik der Urteilskraft. Trad. de Fernando Costa Mattos. Petrópolis: Editora Vozes; Bragança

Paulista: Editora Universitária São Francisco, 2016. (AA 05).

. Textos Seletos. 7 ed. Petrópolis: Vozes, 2011. (Coleção textos filosóficos).

FIGUEIREDO, Vinicius B. "Crítica e Antropologia em Kant". In: SANTOS, L. R. dos. Was is der Mensch?/ Que é o homem? Antropologia, Estética e Teleologia em Kant. Lisboa: Centro de Filosofia de Lisboa, 2010.

KLEIN, Joel Tiago. Kant e a Ideia de uma história universal. São Paulo: Edições Loyola, 2016.

LOUDEN, Robert B. Kant's impure ethics: from rational beings to human beings. USA: Oxford Universtiy Press, 2000.

. "A Segunda parte da Moral: a Antropologia Moral de Kant e sua relação com a Metafisica dos Costumes". Revista Ethic@, Florianópolis, vol 1, nº 1, p. 27-46, 2002.

OLIVEIRA, Manfredo. A. de. A antropologia na filosofia de Kant. Revista de Ciências sociais, vol. IX, nº 1 e 2 pág. 127-140, 1978. 


\section{Lista de Abreviaturas}

As obras de Kant que são utilizadas no presente trabalho são citadas de acordo com as edições disponíveis em português (salvo as obras sem edição nesta língua) e de acordo com a edição da Academia, disponível no site.

Deste modo, as citações obedecerão ao seguinte modelo: KANT, KdU, 05: 35; p. 196, ou seja, primeiramente vem o nome do autor, seguido da abreviação do nome da obra, acompanhado do volume da edição e da página da Academia e o número da página da edição em português. A única exceção é a Crítica da Razão Pura $(\mathrm{KrV})$ que obedecerá a sua forma convencional de referência correspondente à primeira "A" e segunda "B" edição.

Os textos sem edição em português apresentam tradução de minha própria autoria.

As abreviaturas das obras de Kant que utilizei no presente trabalho são as seguintes

AA - Akademie Ausgabe - Edição da Academia (AA)

Anth - Anthropologie in pragmatischer Hinsicht - Antropologia de um ponto de vista pragmático (AA 07)

$\mathrm{Br}$ - Briefe - Cartas (AA 10-13) (AA 04)

GMS - Grundlegung zur Metaphysik der Sitten - Fundamentação da metafísica dos costumes (1785)

IaG - Idee zu einer allgemeinen Geschichte in weltbürgerlicher Absicht - Ideia de uma história universal de um ponto de vista cosmopolita (AA 08)

$\mathrm{KpV}$ - Kritik der praktischen Vernunft - Crítica da razão prática (AA 05)

$\mathrm{KrV}$ - Kritik der reinen Vernunft (Originalpaginierunt A/B) - Crítica da razão pura (paginação original A 1781, B 1789)

KdU - Kritik der Urteilskraft - Crítica da faculdade de julgar (AA 05)

Recebido: 09/12/2019

Aprovado: $07 / 01 / 2020$

Publicado: $26 / 01 / 2020$ 